\title{
Leadership and career development curriculum in Australian dental and oral health programs.
}

\author{
Melanie J. Hayes \\ B. Oral Health, B. Health Science (Hons), MEd, PhD \\ Kelsey Ingram \\ B. Oral Health
}

Dr Melanie Hayes is an Interdisciplinary Senior Lecturer in the Education, Enterprise and Engagement Unit at The University of Sydney. Kelsey Ingram is a Masters of Philosophy candidate at the University of Newcastle.

Corresponding Author:

Melanie J. Hayes

The University of Sydney

City Road, Sydney NSW 2006, Australia

E: melanie.hayes@sydney.edu.au

T: +61286278787

Funding:

This study was funded by the Australasian Council of Dental Schools.

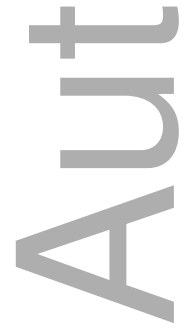

This is the author manuscript accepted for publication and has undergone full peer review but has not been through the copyediting, typesetting, pagination and proofreading process, which may lead to differences between this version and the Version of Record. Please cite this article as doi: $\underline{10.1111 / E J E .12444}$

This article is protected by copyright. All rights reserved 
DR. MELANIE HAYES (Orcid ID : 0000-0003-1001-1267)

\section{Article type : Original Article

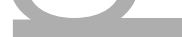 \\ Leadership and career development curriculum in Australian dental and oral health programs.}

\section{ABSTRACT}

Introduction: There is very little evidence of dental schools offering leadership or career development training for students. Given that tertiary students come from diverse backgrounds with differing experiences, it is important that all students learn skills that improve their employability by preparing them for a range of career paths and equipping them with the confidence to lead their profession into the future. This study mapped current leadership and career development training in dental education programs throughout Australia, focusing on the capacity, barriers and enablers. Methods: In 2018, an electronic survey was sent to the Program Convenors of all nineteen dental programs in Australia. Survey questions were sourced from existing literature and the current regulatory competencies.

Results: While the majority of respondents ( $n=17,89 \%$ response rate) indicated that their programs included both leadership training (72\%) and career development activities (88\%), it is clear that the content focus, hours allocated and assessment items vary widely across the country. Further, curriculum appeared to focus almost exclusively on clinical work, which does not provide an avenue for students to explore alternative, non-clinical career options or pathways or develop their skills beyond treating individual patients. Time constraints and ideological differences were reported as the biggest barriers to implementing leadership and career development curricula. 
Conclusion: Despite an inconsistent approach nationally, it appears there is an opportunity for faculty across institutions to collaborate, potentially to develop a set of leadership and career development competencies and best practice teaching and learning activities.

Keywords:

Dental education, leadership, career development, curriculum

\section{INTRODUCTION}

On a global scale, there is a recognised shortage of dental leaders and dental school faculty to lead the dental industry into the future. ${ }^{1,2}$ Commentary in the Australian newspaper has identified that "vacancies at the head of six of Australia's 10 dental schools are creating a ... crisis that requires urgent attention". ${ }^{3}$ Further, an editorial in the Australian Health Review emphasizes that developing visionary leadership is essential, if the dental profession is to address the ever-changing oral health needs of the population. ${ }^{4}$

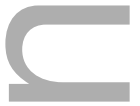

There is very little evidence of dental schools offering formal leadership training for their students. ${ }^{1,5}$ It is an area that is lacking, which is surprising given that undergraduate training would be an ideal time to enthuse and encourage the development of the dental leaders of the future. ${ }^{6}$ Dental students have shown an awareness of the importance of leadership within the profession, including a need for leadership skills in the future. ${ }^{7,8}$ Given that higher education students come from diverse backgrounds with differing experiences, it is important that all students have the opportunity to learn leadership skills that equip them with the skills and confidence to lead their profession into the future, build the image of the profession $^{9}$ and improve their employability by preparing them for alternate career paths.

There are substantial demographic and organizational changes taking place in Australian higher education institutions, including an aging workforce, increased casualization, increases in student enrolments, and changes to teaching and learning methods and delivery, all of which serve to impact on the appeal of academia as a career choice. ${ }^{10}$ Furthermore, the conventional vertical pathway through undergraduate and graduate education, higher-degree research and on into academia is eroding, ${ }^{11}$ whilst the demand for academics is growing. ${ }^{12}$ There is the potential for this dilemma to be addressed through the career transition and employment of clinicians.

This article is protected by copyright. All rights reserved 
Current research has not yet explored what approaches are being used to improve leadership capacity and career development opportunities in dental students. This project aims to address this gap by examining the current curriculum of dental and oral health programs in Australia, as well as exploring the capacity, barriers and enablers to determine the best approach. The study involves comprehensively mapping current career development and leadership training across undergraduate and graduate dental/oral health programs throughout Australia. Opportunities, challenges and barriers to implementation of a leadership course in dental and dental hygiene curricula have been discussed at a conference session of faculty and students in 2012 at the American Dental Education Association Annual Session and Exhibition ${ }^{5}$ but no similar research has been conducted in Australia.

Rather than focus solely on academic dentistry and leadership (which will likely yield little data), this study will explore a range of broad leadership and career development activities; this will allow the researchers to identify both the strengths and gaps of current education programs in the development of future academic leaders, as well as areas where the topic of academic dentistry could be embedded or introduced.

\section{METHODS}

This study was approved by the University of XXX Human Ethics Committee (HREC-20180145).

An electronic survey was prepared which asked participants to identify themes of career development and leadership, as well as the perceived barriers and opportunities to implementing a career development/leadership curriculum within their program. The survey contained two sections, the first section focused on leadership questions and the second dedicated to career development questions. Both sections contain eleven questions each. Career development and leadership-related topics included in the survey have been sourced from a wide range of literature ${ }^{1,6,7,13-15}$ and the current $A D C$ competencies definition of leadership: "reflection and improvement of self, fostering growth in and 
influencing others, and communicating a vision for the future and enabling decisions to align with the goal. To achieve outcomes, leaders embrace the spirit of change and innovation and strategically understand and align complex systems with the goal" ${ }^{16,17}$ The survey also included questions exploring the perceived barriers and opportunities to implementing a career development/leadership curriculum, based on the work of Kalenderian and colleagues. ${ }^{5}$ A definition of career development was also provided, as per the Career Development Association of Australia: "work-related needs and preferences evolve and change continuously throughout life. At the same time, the world of work is continuously evolving and adapting to economic, political and social changes. Career development focuses on enabling people to develop the skills to manage these challenges, make good decisions about their working lives, and maximise their contribution to the communities in which they live and work." ${ }^{18}$ The survey questions were pilot tested among a group of academics for face and content validity. A sample of questions used in the study is provided in Table 1.

An email was sent to the Program Convenors of all nineteen accredited dental and oral health programs in Australia, inviting them to participate in the survey. The email contained a brief description of the survey, a Participant Information Statement and a link to the survey. Completion of the online survey indicated informed consent to participate in the study.

Data from completed surveys was tabulated and reported using descriptive statistics such as percentages and means, and evaluated by both authors.

\section{RESULTS}

Of the 19 programs in Australia, representatives from 17 programs responded, resulting in a response rate of $89 \%$. Nine were oral health programs and eight were dentistry programs; the two programs which did not participate were both from the same institution. Representatives included Heads of School, Coordinators, Discipline Leads and a Teaching and Learning Chair.

\section{Leadership development}

This article is protected by copyright. All rights reserved 
The majority of participants (67\%) indicated that leadership was part of the mission or vision statement for their institution, and that leadership training was a part of the current curriculum (72\%). The primary focus of this training varied greatly and across a variety of courses, as indicated in Figure 1. Many respondents indicated that leadership training was included in clinical practice settings $(n=11)$ and in ethics and professionalism courses $(n=10)$.

The emphasis of leadership training also varied between programs, however many programs placed an emphasis on leadership within public health and health care delivery. These results are displayed in Table 2. The number of hours devoted to leadership training in the curriculum also varied across programs, as displayed in Figure 2. Leadership was primarily assessed using group work activities $(n=13)$, clinical evaluations $(n=8)$ and written assessments $(n=8)$. None of the programs used exams to assess this competency. The majority of participating faculty indicated that students had not shown a desire for additional courses in leadership beyond what are currently offered (50\%), although $31 \%$ were unsure. A number of barriers to implementing leadership training were identified. Time was noted as a barrier by the majority of program convenors $(n=13)$ and ideological differences around the definition of leadership $(n=6)$ and funding $(n=5)$ were also common barriers, while institutional support $(n=2)$ and program interest $(n=2)$ were not an issue for most. Other barriers included cooperation between intra- and inter-disciplinary teams and adequate teaching staff and materials.

Respondents perceived a number of opportunities for facilitating the creation of a leadership development program within the curriculum, including possibilities for collaboration ( $n=11)$, professional development of faculty $(n=12)$ and an increased awareness of importance of leadership in dental profession $(n=13)$. Participants also identified what the ideal leadership development program would need to include (see Figure 3), with the most popular responses focusing on pedagogical practices, such as clear objectives $(n=12)$, practical resources $(n=11)$, well-designed competencies $(n=9)$ and integrated programming $(n=12)$.

\section{Career development}

This article is protected by copyright. All rights reserved 
The majority of participants $(n=14)$ confirmed that career development training was included in the current curriculum. However the focus varied considerably between respondents, with a minority focussing on alternative careers in dentistry $(n=3)$ or specifically a pathway to academia $(n=3)$. The majority $(n=7)$ focussed on other aspects of career development, with workforce readiness and ongoing professional development identified as common themes. Hours devoted to career development varied throughout the programs (see Figure 2). Further, the methods for assessing student's knowledge of skills in career development content varied widely between programs; almost half indicated that they conducted no assessment on this topic at all $(n=6)$, while others used written assessments $(n=4)$, group work $(n=4)$, and portfolios $(n=3)$.

Participants identified multiple opportunities for facilitating the creation of a career development in the dental/oral health curriculum, with the majority recognising that faculty preparation and development (81\%) and collaboration (63\%) were likely positive outcomes. An increased awareness of the importance of career development in the dental profession was identified by $50 \%$ of respondents. There was considerable variability in what respondents thought should be included in the ideal career development program (Table 3).

A range of career development related topics were included in the dental/oral health curriculum, with $100 \%$ of programs including ethical dilemmas and cultural awareness (see Table 4). Less popular topics included organisational change (13.33\%) and personality assessment (18.75\%).

\section{DISCUSSION}

This study has mapped current career development and leadership training across undergraduate and graduate dental/oral health programs throughout Australia, for what appears to be the first time. The majority of respondents indicated that their programs included both leadership training (72\%) and career development activities (88\%), although it is clear that the content focus, hours allocated and assessment items vary widely across the country. These findings are consistent with a study of US dental programs, where aspects of leadership training were embedded in a variety of courses including public health, health care delivery and practice management. ${ }^{19}$ This result highlights the need for a collaborative 
approach to leadership training and career development throughout Australia's oral health programs determining competencies required for leadership. Taichman \& Parkinson suggest that leadership skills can build on competencies students are already working towards, including "communication skills, self-reflection, critical thinking and problem solving and professionalism, ethics and social responsibility." ${ }^{19}$

The biggest barrier to developing a leadership program was time constraints, and this is echoed in US studies pertaining to both academics and students. ${ }^{5}$ Students in first and third years were more likely to participate in extracurricular leadership training while second and fourth years were concluded to be at capacity with course requirements. This should be taken into consideration when implementing a leadership program. Kalenderian and colleagues also concluded that support from senior positions and available resources, financial and human, were needed to execute change. ${ }^{5}$ Given such barriers there is a great opportunity to involve professional associations in this area of the curriculum, particularly given they will provide ongoing support into students practising lives. This collaboration could provide students with opportunities to contribute to their professional association, network and establish mentoring relationships; areas that each indicated room for improvement in the present study. Further, such a collaboration could also help Universities to connect with their alumni to carry out further research in these areas. Ideological differences in the definition of leadership was identified as the second most common barrier among participants. This is despite the fact, and unlike previous studies, a definition of leadership was provided for context.

While the participants of the current study indicated students were not interested in additional leadership training, previous studies have revealed that students believe that leadership can be learnt, and are keen to participate in training. ${ }^{6,7}$ It would be worth surveying students to directly determine their desire for leadership training.

Dental and oral health programs throughout Australia indicated that their career development activities focus on ensuring that students are workforce ready placing emphasis on the clinician. The present study indicated that the highest proportion of leadership training is in a clinical practice settings (64.3\%). One participant commented: 
"There has been a shift away from career development in the curriculum as aspects have and are being further developed through external bodies eg ADA". However, this does not provide an avenue for students' to explore alternative, non-clinical career options or pathways. Kumar \& Khiljee have asserted that healthcare professionals "need to demonstrate effective leadership qualities beyond those needed to treat individual patients". ${ }^{20}$ A definition of career development was provided from the Career Development Association of Australia, however there was an inclination to place responsibility for career development on individuals and continuing professional development. ${ }^{18}$ As a result, participants viewed that there has been a shift away from career development in the curriculum, as aspects have and are being further developed through professional associations.

Mentorship has been indicated as an important component of leadership training ${ }^{15,21}$ however, within Australia it is only included in $50 \%$ of dental and oral health programs. This statistic is concerning, given the Australian Dental Council requires that all dental programs demonstrate that they address competency 2.4 'Engage in mentor/mentee activities and leadership within a health care team' in order to achieve accreditation. Taichman and colleagues state, in reference to leadership, competence is best achieved in an "active learning process" including mentor input. ${ }^{21}$ Further, the many participants in the present study indicated they did not assess career development; by implementing mentorship it will introduce accountability for students to demonstrate learning in an informal manner.

There was agreement among participants in our study that professional preparation and development (81.25\%) and opportunities for collaboration (62.50\%) could facilitate the creation of a career development program. Further, there was high variability in what should be included in a career development program, highlighting the necessity for a collaborative approach. Wardman and colleagues have recently suggested that "our profession is not yet sure of what we mean by leadership or leadership education" ${ }^{22}$ which creates a huge barrier to the development of programs. Victoroff and colleagues have acknowledged the benefit of collaboration between faculty and students in developing leadership programs, ${ }^{6}$ while Kalenderian and colleagues ${ }^{5}$ echo this and include collaboration outside the dental school. It is a recommendation of this study that further collaboration 
between academic staff, students and professional associations be carried out through a conference or forum to facilitate brainstorming and further discussions in this area. This could also lead to conclusions around the competencies and best-practice curriculum required for leadership and career development, using techniques such as the Delphi method.

\section{Limitations}

As with all research, there are some limitations to the present study which are worth noting. The sample size was small ( $n=17)$, however this number did represent some $89 \%$ of dental programs in Australia and has provided new insights into leadership and career development in the dental curriculum. The use of a survey as a data collection method can be limiting, as it relies on self-reporting and it is possible that participants will over-report the inclusion of leadership or career development content within their programs. However, the survey was anonymous, which hopefully encouraged honest responses. Alternative data collection methods such as interviews are more onerous, and while they may have collected richer data, would have likely negatively impacted on the sample size and response rate.

\section{CONCLUSION}

While the majority of dental and oral health programs in Australian report including leadership and career development in the curriculum, it appears the approach is focused on clinical settings and being workforce ready. As identified by the participants, there is an opportunity to collaborate and to facilitate the professional development of faculty, potentially to develop a set of competencies and best practice teaching and learning activities. This would ensure the next generation of dental and oral health graduates are prepared to lead the profession into the future.

\section{ACKNOWLEDGEMENTS}

The author would like to thank the Program Convenors of dental programs in Australia who took time out of their busy schedules to complete the survey. 


\section{REFERENCES}

1. Kalenderian E, Skoulas A, Timothe P, Friedland B. Integrating leadership into a practice management curriculum for dental students. Journal of dental education. 2010 May 1;74(5):464-71.

2. Kassebaum DK, Hendricson WD, Taft T, Haden NK. The dental curriculum at North American dental institutions in 2002-03: a survey of current structure, recent innovations, and planned changes. Journal of Dental Education. 2004 Sep 1;68(9):914-31.

3. Booth, M. Dental schools left with holes. The Australian. 10 October 2014. At: https://www.theaustralian.com.au/higher-education/education-council-warns-ofvacancies-at-top-of-dental-schools/newsstory/5274f98484069ae449a870a94f2e332a Accessed: 23 March 2018

4. Kruger E, Heitz-Mayfield L, Tennant M. Sustaining supply of senior academic leadership skills in a shortage environment: a short review of a decade of dental experience, Australian Health Review. 2014 Jun 26;38(3):243-5.

5. Kalenderian E, Taichman RS, Skoulas A, Nadershahi N, Victoroff KZ. Developing the next generation of leaders in oral health. Journal of dental education. $2013 \mathrm{Nov}$ 1;77(11):1508-14.

6. Victoroff KZ, Schneider K, Perry C. Tomorrow's leaders, starting today: a pilot leadership development program for dental students. Journal of dental education. $2009 \operatorname{Mar} 1 ; 73(3): 311-8$.

7. Victoroff KZ, Schneider K, Perry C. Leadership development for dental students: what do students think? Journal of dental education. 2008 Sep 1;72(9):982-8.

8. Taipale H, Tuononen TA, Suominen AL. Fifth-year dental students' visions of leadership-A qualitative study. European Journal of Dental Education. 2018 Nov;22(4):272-80.

9. Australian Dental Council. Professional Attributes and competencies of the newly qualified dentist 2010. At: https://www.adc.org.au/Publications-andforms/Accreditation-publications Accessed: 10 Feb 2018. 
10. Coates H, Dobson IR, Goedegebuure L, Meek L. Australia's casual approach to its academic teaching workforce. 2009. LH Martin Institute, Australian Council for Educational Research.

11. Edwards D, Bexley E, Richardson S. Regenerating the academic workforce: The careers, intentions and motivations of higher degree research students in Australia: Findings of the National Research Student Survey (NRSS). 2011.

12. Coates H, Goedegebuure L. Recasting the academic workforce: Why the attractiveness of the academic profession needs to be increased and eight possible strategies for how to go about this from an Australian perspective. Higher Education. 2012 Dec 1;64(6):875-89.

13. Kelley CA, Bridges C. Introducing professional and career development skills in the marketing curriculum. Journal of Marketing Education. 2005 Dec 1;27(3):212-8.

14. Taichman RS, Green TG, Polverini PJ. Creation of a scholars program in dental leadership (SPDL) for dental and dental hygiene students. Journal of dental education. 2009 Oct 1;73(10):1139-43.

15. Hammer DA, Nadershahi NA. Assessing the demand and preferred format of a student leadership development program at Pacific. Journal of dental education. 2011 Aug 1;75(8):1044-52.

16. Australian Dental Council. Professional competencies of the newly qualified dentist. 2016. At: https://www.adc.org.au/Resource-And-Publications/Accreditation-FormsDocuments Accessed: 20 March 2018.

17. Australian Dental Council. Professional competencies of the newly qualified dental hygienist, dental therapist and oral health therapist. 2016. At:

https://www.adc.org.au/Resource-And-Publications/Accreditation-Forms-Documents Accessed 20 March 2018.

18. Career Development Association of Australia. 2018 At: https://www.cdaa.org.au/about-career-development Accessed: 17 Feb 2018

19. Taichman RS, Parkinson JW. Where is leadership training being taught in US dental schools?. Journal of dental education. 2012 Jun 1;76(6):713-20.

20. Kumar, RDC \& Khiljee, N. Leadership in healthcare. Anaesthesia \& Intensive Care Medicine. 2016 Jan;17(1):63-5. 
21. Taichman RS, Parkinson JW, Nelson BA, Nordquist B, Ferguson-Young DC, Thompson JF. Program design considerations for leadership training for dental and dental hygiene students. Journal of dental education. 2012 Feb 1;76(2):192-9.

22. Wardman MJ, Ford J, Manogue M. Undergraduate leadership education for dentistry: preparing for practice. European Journal of Dental Education. 2017;21(4):e109-13.

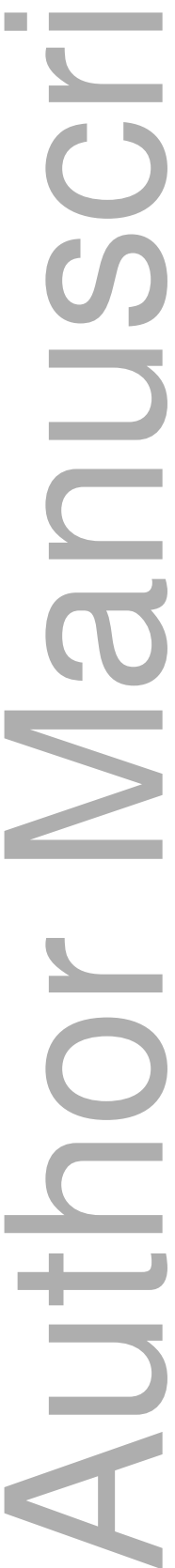


Tables and Figures

Table 1: Sample of survey questions

\begin{tabular}{|c|c|}
\hline $\begin{array}{l}\text { Question } \\
\text { number }\end{array}$ & Question \\
\hline 2 & Is leadership training part of the current curriculum at your institution? \\
\hline 5 & On what areas of dentistry does your leadership training program focus? \\
\hline 7 & $\begin{array}{l}\text { How is leadership evaluated to address ADC Competency } 2.4 \text { Engage in mentor/mentee } \\
\text { activities and leadership within a health care team? }\end{array}$ \\
\hline 11 & What would the ideal leadership development program look like \\
\hline 19 & $\begin{array}{l}\text { What barriers do you perceive to the creation of a career development program in the } \\
\text { dental curriculum? }\end{array}$ \\
\hline 20 & $\begin{array}{l}\text { What opportunities do you perceive that could facilitate the creation of a career } \\
\text { development program in the dental curriculum? }\end{array}$ \\
\hline
\end{tabular}

Table 2: Leadership training focus by areas of dentistry

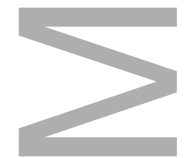

health care delivery:

public health:

legal aspects of

profession:

academic dentistry:

practice management:

business:

organised dentistry:

Strong Moderate
emphasis emphasis

$\% \quad n \quad \% \quad n$

26.7

35.7

7

4

33.3

5

$5 \quad 21.4$

$\begin{array}{lll}15.4 & 2 & 38.5\end{array}$

$5 \quad 38.5$

Some

Not

$\begin{array}{lll}21.4 & 3 & 14.3\end{array}$

$\begin{array}{lll}0.0 & 0 & 46.2\end{array}$

$\begin{array}{ll}2 & 35.7\end{array}$

$6 \quad 23.1$

$\begin{array}{lll}0.0 & 0 & 30.8\end{array}$

$\begin{array}{ll}4 & 30.8\end{array}$

0.0

$\begin{array}{ll}0 & 16.7\end{array}$

258.3

$\begin{array}{ll}7 & 16.7\end{array}$

$5 \quad 0.0$

0

1

7.7

1

57.1

3

$3 \quad 15.4$

2

2

23.1

2

8.3

1

2.8

3.0

Table 3: Inclusions for the ideal career development program

\begin{tabular}{|r|r|r|}
\hline & $\%$ & $\mathrm{n}$ \\
\hline
\end{tabular}




\begin{tabular}{|l|c|c|}
\hline Practical information/resources & 75.00 & 12 \\
\hline Clear objectives & 56.25 & 9 \\
\hline Longitudinal or integrated programming & 50.00 & 8 \\
\hline Well-designed career development competencies & 37.50 & 6 \\
\hline Workshops & 37.50 & 6 \\
\hline Small core courses & 31.25 & 5 \\
\hline Student-driven programming & 31.25 & 5 \\
\hline
\end{tabular}

Table 4: Career development related topics included in the curriculum.

\begin{tabular}{|l|r|r|r|r|r|}
\hline & \multicolumn{2}{|c|}{ Yes } & \multicolumn{2}{|c|}{ Notal } \\
\hline & \multicolumn{1}{|l|}{$\%$} & $\mathrm{n}$ & $\mathrm{n}$ & $\mathrm{n}$ \\
\hline Ethical dilemmas & 100.00 & 16 & 0.00 & 0 & 16 \\
\hline Cultural awareness & 100.00 & 15 & 0.00 & 0 & 15 \\
\hline Effective communication skills & 93.75 & 15 & 6.25 & 1 & 16 \\
\hline Self-reflection & 93.75 & 15 & 6.25 & 1 & 16 \\
\hline Public speaking/presentation skills & 87.50 & 14 & 12.50 & 2 & 16 \\
\hline Volunteerism & 86.67 & 13 & 13.33 & 2 & 15 \\
\hline Self-awareness and self-management & 75.00 & 12 & 25.00 & 4 & 16 \\
\hline Academic dentistry (teaching and research careers) & 75.00 & 12 & 25.00 & 4 & 16 \\
\hline Goal-setting & 68.75 & 11 & 31.25 & 5 & 16 \\
\hline Self-improvement & 68.75 & 11 & 31.25 & 5 & 16 \\
\hline Career planning & 66.67 & 10 & 33.33 & 5 & 15 \\
\hline Leadership/contribution to professional associations & 66.67 & 10 & 33.33 & 5 & 15 \\
\hline Advocacy and influencing others & 56.25 & 9 & 43.75 & 7 & 16 \\
\hline Organisational skills & 56.25 & 9 & 43.75 & 7 & 16 \\
\hline Emotional intelligence & 50.00 & 8 & 50.00 & 8 & 16 \\
\hline Networking opportunities & 50.00 & 8 & 50.00 & 8 & 16 \\
\hline Team-building & 50.00 & 8 & 50.00 & 8 & 16 \\
\hline Mentoring & 8 & 50.00 & 8 & 16 \\
\hline
\end{tabular}

This article is protected by copyright. All rights reserved 


\begin{tabular}{|l|r|r|r|r|r|}
\hline Work-life balance/integration & 43.75 & 7 & 56.25 & 9 & 16 \\
\hline Practice Management & 43.75 & 7 & 56.25 & 9 & 16 \\
\hline Non-dental leadership roles & 43.75 & 7 & 56.25 & 9 & 16 \\
\hline Conflict resolution/management & 42.86 & 6 & 57.14 & 8 & 14 \\
\hline Being a clinical team leader & 31.25 & 5 & 68.75 & 11 & 16 \\
\hline Assessment of leadership competencies & 26.67 & 4 & 73.33 & 11 & 15 \\
\hline Negotiations & 26.67 & 4 & 73.33 & 11 & 15 \\
\hline Personality assessment & 18.75 & 3 & 81.25 & 13 & 16 \\
\hline Organisational change & 13.33 & 2 & 86.67 & 13 & 15 \\
\hline
\end{tabular}

This article is protected by copyright. All rights reserved 
Figure 1: Courses in which leadership training is provided in program

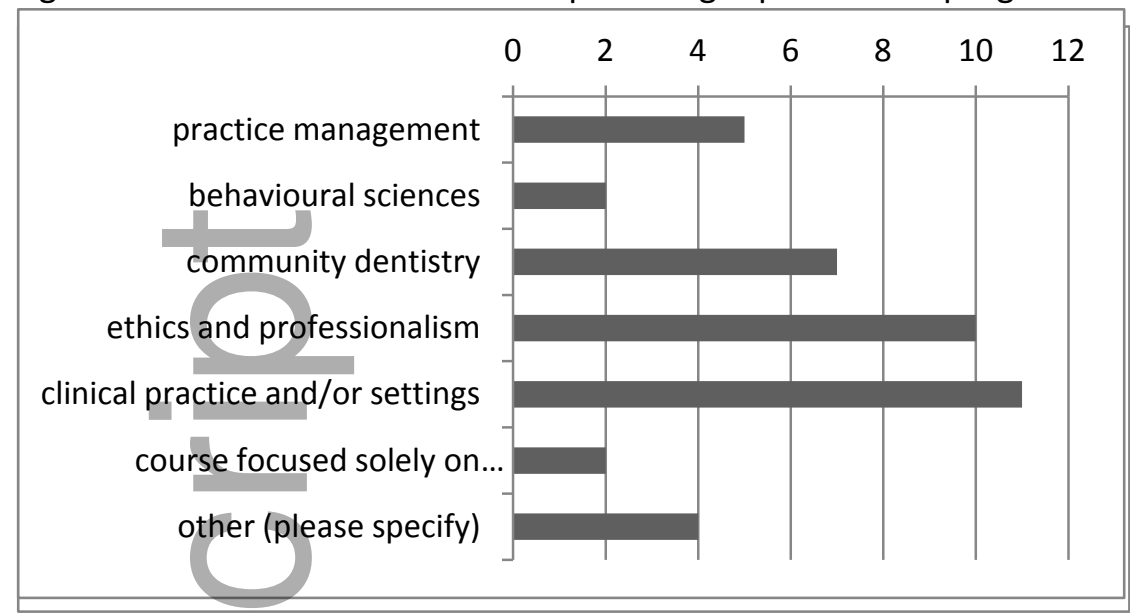

Figure 2: Hours in the curriculum devoted to leadership and career development

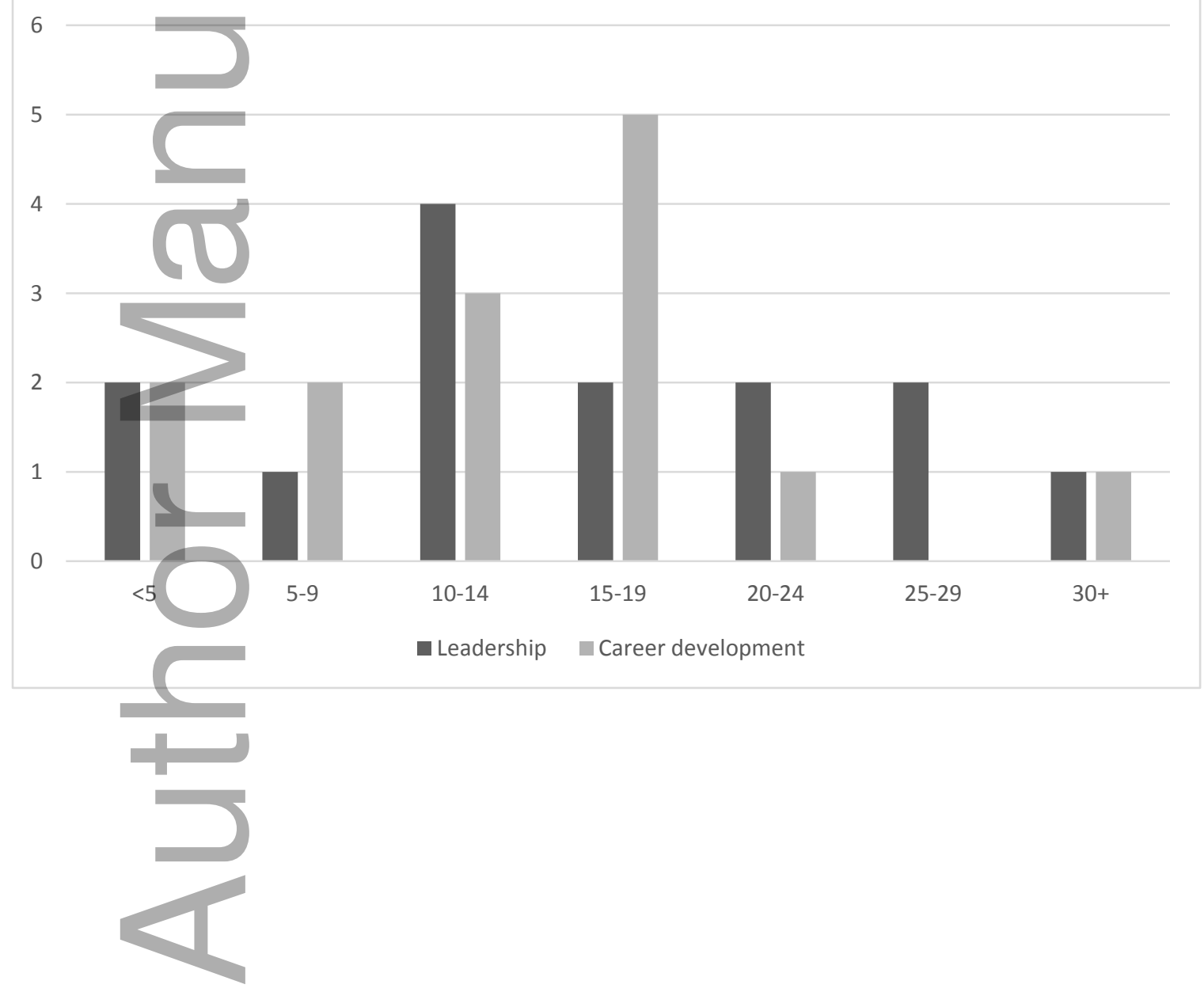


Figure 3: Characteristics of an ideal leadership development program

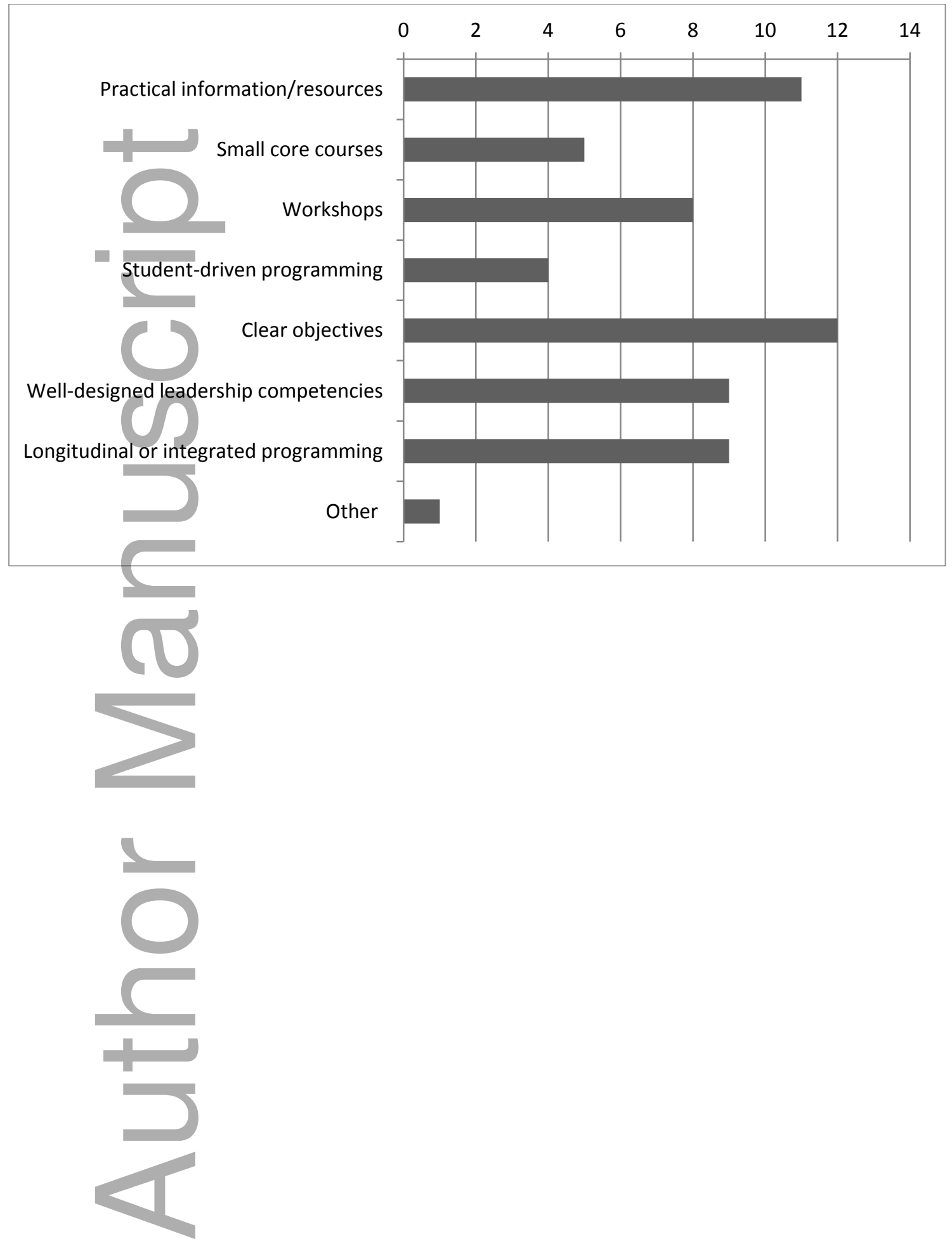

This article is protected by copyright. All rights reserved 


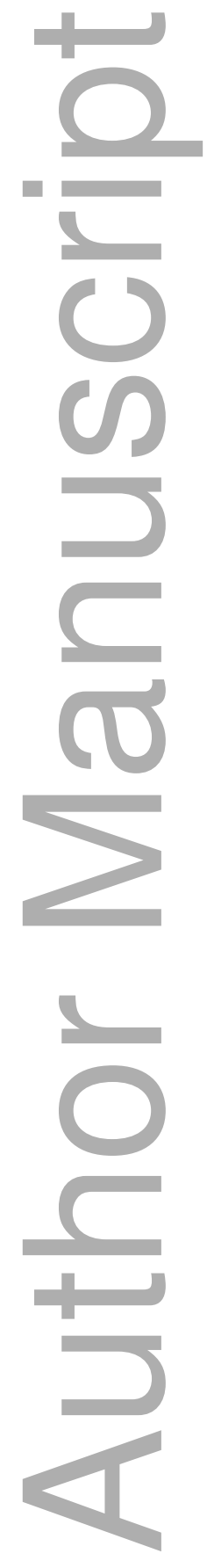

This article is protected by copyright. All rights reserved 


\section{University Library}

\section{- M M N E R VA A gateway to Melbourne's research publications}

Minerva Access is the Institutional Repository of The University of Melbourne

Author/s:

Hayes, MJ;Ingram, K

Title:

Leadership and career development curriculum in Australian dental and oral health programmes

Date:

2019-08-01

Citation:

Hayes, M. J. \& Ingram, K. (2019). Leadership and career development curriculum in Australian dental and oral health programmes. EUROPEAN JOURNAL OF DENTAL EDUCATION, 23 (3), pp.378-384. https://doi.org/10.1111/eje.12444.

Persistent Link:

http://hdl.handle.net/11343/285931 